\title{
Milliliter per Cage
}

National Cancer Institute

\section{Source}

National Cancer Institute. Milliliter per Cage. NCI Thesaurus. Code C73750.

A dose calculation unit expressed in milliliter(s) per cage. 